\title{
Use of functional performance tests in sports: Evaluation proposal for football players in the rehabilitation phase
}

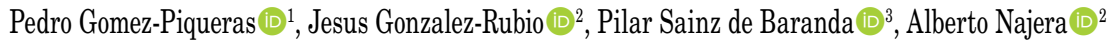 \\ ${ }^{1}$ Department of Physical Education, University Castilla La Mancha, Albacete, Spain \\ ${ }^{2}$ Department of Medical Sciences, University Castilla La Mancha, Albacete, Spain \\ ${ }^{3}$ Department of Sport Sciences, University Murcia, Albacete, Spain
}

Received: March 09, 2017 Accepted: June 08, 2017 Published online: May 15, 2018

\begin{abstract}
Objectives: Based on the criteria of a group of experts, this study aims to select a set of functional performance tests which can be applied to evaluate the functional status of a football player in the recovery process and make a decision in relation to their return to practice.

Materials and methods: A total of 16 experts were selected by the coordinator group to judge an initial list of functional performance tests and, thus, reach a consensus about the tests which are best suited to the needs of the injured player. Each of the experts had to evaluate each one of the tests in a scale from 1 to 5 in relation to their suitability. Delphi method was used to reach consensus in the expert group.

Results: From the initial list of 25, the tests which obtained the best evaluation were: Counter movement jump (4.3 \pm 0.9$)$, Single hop test (4.1 \pm 0.8$)$, Triple hop test $(4.1 \pm 0.9)$, Crossover hop test (4.1 \pm 0.7$)$, Yo-Yo intermittent recovery (4.2 \pm 0.6$)$, Barrow test (4.1 \pm 0.6$)$, Shuttle run $8 \times 5 \mathrm{~m}(4.1 \pm 0.8)$. Star excursion balance test $(4 \pm 0.7)$ and Y balance test $(4.1 \pm 0.7)$.

Conclusion: In the opinion of the experts selected here, these tests are the ones which best respond to the needs involved in a complex decision such as RTP.
\end{abstract}

Keywords: Expert; injury; recovery; return to play; testing.

In recent years, the evaluation methods of injured athletes to return to play (RTP) have been questioned. ${ }^{[1,2]}$ Downplaying the importance of this decision for the functional evaluation previously indicated by Cook et $\mathrm{al},{ }^{[3]}$ appears to be one of the reasons.

The difference between a functional performance test (FPT) and a clinical test consists in the overall movement approach which the first test performs. ${ }^{[4]}$ A clinical test involves a single part of the body and does not inform about the ability to perform in a sports task. ${ }^{[5]}$ Measuring variables such as flexibility, strength, endurance, coordination and balance in an isolated way and without integrating them in a movement may cause us to believe that the tissue is cured when functionally this is not the case. ${ }^{[6]} \mathrm{In}$ turn, it is necessary to highlight the psychological importance which these types of FPTs provide.
If an athlete verifies his capacity to perform in environments and movements similar to his sports modality, his confidence will also increase. ${ }^{[7]}$

The major importance placed on the FPT by the Heads of Sports Clubs is high, ${ }^{[8]}$ and the same tests have already been used to predict the injury of the lower $\operatorname{limb}^{[9]}$ or to determine the RTP of an athlete. ${ }^{[10]}$ However, the identification issue of the most appropriate tests still remains unresolved. ${ }^{[1]}$

To evaluate the correct functionality of the lower limbs (which are priorities in football players), a series of necessary components have been identified which every functional evaluation must include: balance, strength, endurance, coordination, agility, control in different planes, lift-off and landing in hops, knee and hip alignment, acceleration, deceleration, braking and

Corresponding author: Pedro Gomez-Piqueras, MD. Department of Physical Education, University Castilla La Mancha, 02071 Albacete, Spain. 
change of direction. ${ }^{[8]}$ In the absence of a sophisticated laboratory and instruments to carry out the kinematic and kinetic analysis, there is currently no measurement instrument other than the FPT to carry out the functional evaluation of the lower limbs. ${ }^{[12]}$

The authors including Austin, ${ }^{[5]}$ Molano $^{[13]}$ and Reiman and Manske ${ }^{[14]}$ indicate that the most frequently used tests with the best psychometric properties are: strength (hop tests and their variations), endurance (Cooper test, Course navette, Probst test and the Yo-Yo intermittent endurance test), speed (Shuttle run test), agility (Illinois test, the $\mathrm{T}$ test and the Barrow test), and stability and posture control (Star excursion balance test, the $\mathrm{Y}$ balance test and Four square test).

In the present study, we aimed to select, thanks to the collaboration of a group of experts in RTP evaluation, a set of FPTs which can be applied in a simple, quick and efficient way to evaluate the functional status of a football player who is in the last phase of his rehabilitation process after an injury.

\section{MATERIALS AND METHODS}

A group of 20 experts was selected in an intentional way based on their knowledge of the field and their professional experience as a fitness coach or injury rehab fitness coach in professional football (Spanish $1^{\text {st }}$ and $2^{\text {nd }}$ Divisions).

Due to their availability, of 20 initially selected experts, 16 were finally included in the study. Thus, the group of experts was comprised by 16 subjects (males) with a mean professional experience of $11.1 \pm 6.8$ years. Seven experts (43.75\%) performed their jobs as fitness coach and nine (56.25\%) as rehab fitness coach. They all do their jobs in the Spanish first and second Division Football teams.

A coordinator group, comprised by the authors of this study, was in charge of contacting, reporting and synthesizing the information which the experts provided. The interaction with the group of experts was by means of e-mail respecting the anonymous nature of the issued opinions. According to the Declaration of Helsinki for medical research involving human subjects, all the experts were previously informed of the study's objectives and the methodology to be used.

All procedures developed in this study was approved and consented by the Ethics Committee of the University of Castilla-La Mancha (Institutional
Board). The study was conducted in accordance with the principles of the Declaration of Helsinki.

\section{Battery of proposed tests}

Table 1 shows the proposed list of 25 FPTs grouped by the predominant physical capacity. ${ }^{[15-33]}$ Each of the experts had to evaluate each one of the tests in a scale from 1 to 5 in relation to their suitability for injured football players in the last recovery phase. A 5 point score would correspond to "Very good suitability" and a 1 point score to "Very poor suitability". Each expert would also have the option to evaluate each specific and general proposal in an open and qualitative way.

Several considerations which the coordinator group indicated as important to be analyzed by the experts were:

- The test should represent the relevant functional parameters to play football.

Table 1. Initial porpoise of functional performance test

\begin{tabular}{|c|c|}
\hline & Functional performance test \\
\hline \multirow[t]{7}{*}{ Strength } & Single hop test ${ }^{[15]}$ \\
\hline & Triple hop test $\mathrm{t}^{[15]}$ \\
\hline & Crossover hop test ${ }^{[15]}$ \\
\hline & Leap test ${ }^{[15]}$ \\
\hline & RM test ${ }^{[16]}$ \\
\hline & Hexagon test $\mathrm{t}^{[17]}$ \\
\hline & $\mathrm{CM} J^{[18]}$ \\
\hline \multirow[t]{8}{*}{ Endurance } & Cooper's test $\mathrm{t}^{[19]}$ \\
\hline & $15^{\prime}$ test $^{[20]}$ \\
\hline & Course navette ${ }^{[21]}$ \\
\hline & Probst test ${ }^{[22]}$ \\
\hline & Yo-Yo endurance test ${ }^{[23]}$ \\
\hline & Yo-Yo intermittent recovery ${ }^{[23]}$ \\
\hline & Sprints multiple test ${ }^{[23]}$ \\
\hline & Rockport walk test ${ }^{[24]}$ \\
\hline \multirow[t]{5}{*}{ Speed/agility } & Shuttle run $10 \mathrm{~m}^{[25]}$ \\
\hline & Shuttle run $8 \times 5 \mathrm{~m}^{[26]}$ \\
\hline & Illinois test ${ }^{[27]}$ \\
\hline & Barrow test (Zig-zag run test) ${ }^{[28]}$ \\
\hline & T test ${ }^{[29]}$ \\
\hline \multirow[t]{5}{*}{ Postural control } & Single leg balance test ${ }^{[30]}$ \\
\hline & Romberg test \\
\hline & Star excursion balance test ${ }^{[31]}$ \\
\hline & Y balance test ${ }^{[32]}$ \\
\hline & Four square test ${ }^{[33]}$ \\
\hline
\end{tabular}


- The test should be suitable for the athlete's status in the last week of his rehabilitation prior to the return with the team.

- The test should be quick to apply and score.

- The test should require little space and material so that it can be performed in different scenarios.

- The test should be safe.

- The test should be well accepted by the athlete as well as motivational.

\section{Procedures}

The validation of the tests by the group of experts was carried out by means of the "Modified Delphi" technique ${ }^{[34]}$ with the following steps: definition of the problem, training of the experts group, design of the battery tests for the evaluation, delivery of the material to the experts, quantitative analysis evaluations, initial proposed modification, delivery of second battery tests, second evaluations analysis, report preparation with data analysis and final information of the obtained results to the experts group.

\section{Statistical analysis}

To determine the competency coefficient (K) for each one, the experts applied the questionnaire proposed by the State Committee for Science and Technology of the USSR (1971) where they indicated the perceived self-knowledge on the subject in question. This coefficient is obtained by applying the following formula, $\mathrm{K}=1 / 2(\mathrm{Kc}+\mathrm{Ka})$, where $\mathrm{Kc}$ is the coefficient of knowledge that the expert has about the subject or problem raised (0-10) multiplied by 0.1 and $\mathrm{Ka}$ is the coefficient of argumentation (0-1). If $K \geq 0.8$ the competence level of the expert is high, if $K \geq 0.5$ and

Table 2. Descriptive analysis with expert group answers

\begin{tabular}{|c|c|c|c|}
\hline & \multirow[t]{2}{*}{ Functional performance test } & \multirow{2}{*}{$\frac{\text { Mean assessment }(1-5)}{\text { Mean } \pm \mathrm{SD}}$} & \multirow{2}{*}{$\frac{\text { Aiken V }}{p}$} \\
\hline & & & \\
\hline \multirow[t]{7}{*}{ Strength } & Single hop test & $4.1 \pm 0.8$ & 0.77 \\
\hline & Triple hop test & $4.1 \pm 0.9$ & 0.77 \\
\hline & Crossover hop test & $4.1 \pm 0.7$ & 0.77 \\
\hline & Leap test & $2.7 \pm 0.7$ & 0.42 \\
\hline & RM test & $2.5 \pm 1.0$ & 0.37 \\
\hline & Hexagon test & $2.8 \pm 0.9$ & 0.45 \\
\hline & $\mathrm{CMJ}$ & $4.3 \pm 0.9$ & 0.82 \\
\hline \multirow[t]{8}{*}{ Endurance } & Cooper's test & $1.9 \pm 0.7$ & 0.22 \\
\hline & $15^{\prime}$ test & $2.2 \pm 0.9$ & 0.30 \\
\hline & Course navette & $2.8 \pm 0.7$ & 0.45 \\
\hline & Probst test & $3.6 \pm 0.8$ & 0.65 \\
\hline & Yo-Yo endurance test & $3.8 \pm 0.6$ & 0.70 \\
\hline & Yo-Yo intermittent recovery & $4.2 \pm 0.6$ & 0.80 \\
\hline & Multiple sprints test & $3.9 \pm 0.6$ & 0.72 \\
\hline & Rockport walk test & $1.5 \pm 0.9$ & 0.12 \\
\hline \multirow[t]{5}{*}{ Speed/agility } & Shuttle run $10 \mathrm{~m}$ & $3.6 \pm 0.7$ & 0.65 \\
\hline & Shuttle run $8 \times 5 \mathrm{~m}$ & $4.1 \pm 0.8$ & 0.77 \\
\hline & Illinois test & $3.3 \pm 0.9$ & 0.57 \\
\hline & Barrow test (Zig-zag run test) & $4.1 \pm 0.6$ & 0.77 \\
\hline & $\mathrm{T}$ test & $3.8 \pm 0.7$ & 0.70 \\
\hline \multirow[t]{5}{*}{ Postural control } & Single leg balance test & $3.6 \pm 0.8$ & 0.65 \\
\hline & Romberg test & $2.2 \pm 1.0$ & 0.30 \\
\hline & Star excursion balance test & $4.0 \pm 0.7$ & 0.75 \\
\hline & Y balance test & $4.1 \pm 0.7$ & 0.77 \\
\hline & Four square test & $2.8 \pm 0.7$ & 0.45 \\
\hline
\end{tabular}


$<0.8$ the competence level is medium and if $\mathrm{K}<0.5$ the competence level is low.

Next, once the evaluations were obtained which were carried out on the proposed battery tests, the Aiken $\mathrm{V}$ test ${ }^{[35]}$ was used to determine the agreement between the experts and the validity of the contents.

Finally, descriptive analysis (mean and standard deviation) and internal consistency (Cronbach alpha) were performed using the IBM SPSS version 22.0 statistical package (IBM Corp., Armonk, NY, USA).

\section{RESULTS}

\section{Quantitative evaluation}

The competency coefficient obtained by the experts group was found to be high $(0.84 \mathrm{~K})$. Having calculated the descriptions for each test and their agreement level between the judges (Aiken V) (Table 2), the tests with an average evaluation above 4 and an Aiken $\mathrm{V}>0.75$ were selected.

The Single hop test, Triple hop test, Crossover hop test, CMJ, Yo-Yo intermittent recovery, Shuttle run $8 \times 5 \mathrm{~m}$, Barrow test, Star excursion balance test and the $\mathrm{Y}$ balance test were the tests selected due to their higher evaluations.

The tests which had a history of lower use by the professional staff from the Spanish Football first and second Divisions were the Leap test and the Rockport walk where $56.2 \%$ of the experts had never used them and the Romberg test and the Four square test with $37.5 \%$.

The Cronbach alpha value for the estimate of the reliability of the final proposal was 0.72 .

\section{Qualitative evaluation}

Despite failing to obtain sufficient support to be included in the presented battery, the following tests were suggested by several experts to be considered in the overall evaluation: Drop jump test or the effort character for strength, the Bucheit test 30:15 for endurance and the Functional Movement Screen (FMS). ${ }^{[3]}$

The lack of consensus to include several additional tests among the initially selected ones indicated that the second round of evaluation included in the steps followed by the Delphi method were unnecessary.

In relation to the supplied general observations section, we highlight the recommendations related to the use of one test or another based on the type and location of the injury, as well as the importance of evaluating not only the level achieved in the test, but also the functional pattern used.

\section{DISCUSSION}

Due to the complex nature of the sports injury and its recovery, ${ }^{[36]}$ a decision such as RTP cannot adopt a "black or white" paradigm. ${ }^{[37]}$ Therefore, today, it is more difficult to make a decision than 20 or 30 years ago, when the sports context was less competitive, the multi-factor connotations of the injury were not taken into account and the literature provided lists of medical and functional factors categorized in absolute and relative terms for the sports practice. ${ }^{[38]}$

The main objective of the present study was to evaluate the opinion of experts on the use of FPTs in the RTP process in professional football players. Based on the knowledge of the authors, this is the first Delphi work that determines the best FPTs that can guide trainers and health care professionals to decide the optimum time and situation for RTP. It is difficult to recruit and retain participants in Delphi studies conducted in sports, possibly due to the high competing interests and unwillingness to disclose details of their own internal protocols. ${ }^{[39]}$ Recently, the Delphi technique has been used in English professional teams to determine the best RTP criteria in hamstring muscle injury.

The strength of the consensus reached in this study was reflected by the remarkable high agreement between the selected experts. A list of nine FPTs was defined as the most appropriate to determine the optimal functional predisposition of a player in the recovery from an injury. This number reflects the complexity of RTP. ${ }^{[36]}$

There is no experience in which the FPTs selected by the experts group were used with injured football players in a simultaneous way. We verify that the use of these tests in an isolated way, combined with other tests or with different aims, frequently appear in several studies. ${ }^{[1]}$

Thus, in reference to the best evaluated strength tests, we confirmed how the CMJ was presented as a reliable test, with easy implementation and low fatigue ${ }^{[40]}$ on the other hand, due to their unilateral and measurement capacity and minimal required equipment, the Single hop, Triple hop and Crossover hop tests have been included in multiple studies about injured athletes. ${ }^{[15,41]}$ 
In relation to the endurance tests and capacity to repeat efforts and recover among the same tests, it was found that a poor physical condition level in this aspect, at least in reference to muscular and tendon injuries, is a potential injury risk factor. ${ }^{[42]}$ The Yo-Yo intermittent recovery due to its extensively generalized use and its sensitivity to detect changes in the performance, ${ }^{[43]}$ is a useful and valid test for our objective.

With regards to the evaluation of the athlete's capacity to quickly change direction (Agility/ Speed), despite being a critical component of the performance ${ }^{[44,45]}$ there is no frequency of significant use, perhaps due to the existence of numerous tests for this capacity, which serve us as reference.

Specifically for this study and this capacity, the best options evaluated by the experts were the $5 \mathrm{~m}$ Shuttle run sprint test and the Barrow test. The first test was recommended by Chaouachi et al. ${ }^{[46]}$ and was demonstrated as valid by ${ }^{[47]}$ while the second test has presented the recommended and optimum psychometric values which encourage its use..$^{[48]}$

Finally, in relation to posture control, we verified that this skill was evaluated as relevant to reduce the risk of injury and its relapse. ${ }^{[49,50]}$ The use of tests such as the Star excursion balance test ${ }^{[31]}$ and its variation, the $\mathrm{Y}$ balance test, ${ }^{[32]}$ due to their simplicity, low cost and good psychometric properties, ${ }^{[31,51]}$ is more than justified.

The appraisal of the literature supporting the validity of each FPT is beyond the scope of this work. In general, the measurement properties of FPT and their utility for RTP are either poor or have never been investigated so future research should evaluate this validity to standardize functional capacity assessment. ${ }^{[36]}$

\section{Limitations and practical implications}

- The selection of a group of experts was carried out based on the subjective criteria of the coordinator group (knowledge of the performed work) and objectives (performance in one of the main categories of the Spanish professional football league). It would be interesting to increase the number and requirement level of the objective arguments used.

- Although a minimum of 10 experts is recommended for the studies with the Delphi method, it would be recommendable to increase their number to prevent abandonments due to the long-term methodological process and increase the robustness of the obtained data.
- Although the initial tests selection was based on the review of the prior literature, it is probable that some relevant test was not mentioned since it was not known by the experts. We recommend new reviews, supported on this study, which explore this potential lack at a more in-depth level.

- At the time of using a test with an injured athlete, the type of injury, the sports modality, and the injury's severity are variables which condition the selection of one test or another. In this study, we have treated the injury in a generic way without considering these variables which may have conditioned the evaluations of the tests. We propose creating batteries of tests adapted to the type of injury and the sports modality.

- The proposal presented here is framed within a context of limited resources, thus, the replication of this experience focusing it on teams with greater material resources would be an interesting alternative.

In conclusion, we highlight that the absence of similar experiences which aim to specify the most useful tests when evaluating the last phase of an injured football player and demonstrate the originality of this study by establishing an interesting starting point to be taken into account in future investigations.

The FPTs most suitable for use with an injured football player in his final week of rehabilitation prior to the return to his group practice, based on the opinions of the 16 expert fitness coaches and rehab fitness coaches who work in the Spanish Football first and second Divisions, are the CMJ, Single hop test, Triple hop test and Crossover hop test for strength, the Yo-Yo intermittent recovery for endurance, the Barrow test and the Shuttle run $8 \times 5 \mathrm{~m}$ for agility/speed and the Star excursion balance test and the $\mathrm{Y}$ balance test for the posture control.

The consensus achieved in this study should encourage the professionals in this field to contribute reference data for these tests in their different contexts to accordingly establish comparisons by ages, levels or demarcations and hence, evaluate and compare the degree of functional achievement reached by the injured person not only in relation to their previous status, but also in relation to a similar collective.

\section{Acknowledgements}

To all the members who participated in the experts group, for their essential and unselfish collaboration. In alphabetical 
order: Oscar Caro (Ad Alcorcón), Miguel Ángel Campos (UD Levante), Moisés del Hoyo (Sevilla FC), Cesar Fernández (SD Ponferradina), Julio Hernando (Real Valladolid), Francisco Javier Molano (Real Betis), José Alfonso Morcillo (Granada CF), Víctor Paredes (Rayo Vallecano), Alberto Piernas (Albacete Bpie), Javier Poveda (Córdoba CF), Fernando Rodríguez (Deportivo de la Coruña), Lluis Sala (Girona CF), José María Sanz (Córdoba CF), Juan Solla (Málaga CF) and Andrés Ubieto (Real Zaragoza).

\section{Declaration of conflicting interests}

The authors declared no conflicts of interest with respect to the authorship and/or publication of this article.

\section{Funding}

The authors received no financial support for the research and/or authorship of this article.

\section{REFERENCES}

1. Brumitt J, Heiderscheit BC, Manske RC, Niemuth PE, Rauh MJ. Lower extremity functional tests and risk of injury in division iii collegiate athletes. Int J Sports Phys Ther 2013;8:216-27.

2. Pigozzi F, Giombini A, Macaluso A. Do current methods of strength testing for the return to sport after injuries really address functional performance? Am J Phys Med Rehabil 2012;91:458-60.

3. Cook G, Burton L, Hoogenboom B. Pre-participation screening: the use of fundamental movements as an assessment of function - part 1. N Am J Sports Phys Ther 2006;1:62-72.

4. Okada T, Huxel KC, Nesser TW. Relationship between core stability, functional movement, and performance. J Strength Cond Res 2011;25:252-61.

5. Austin GP. Functional testing and Return to activity. In: Magee D, Zachazewski J, Quillen W, editors. Scientific foundations and principles of practice in musculoskeletal Rehabilitation. St Louis: Saunders; 2007. p. 633-64.

6. Creighton DW, Shrier I, Shultz R, Meeuwisse WH, Matheson GO. Return-to-play in sport: a decision-based model. Clin J Sport Med 2010;20:379-85.

7. Ardern CL, Bizzini M, Bahr R. It is time for consensus on return to play after injury: five key questions. Br J Sports Med 2016;50:506-8.

8. Haitz K, Shultz R, Hodgins M, Matheson GO. Test-retest and interrater reliability of the functional lower extremity evaluation. J Orthop Sports Phys Ther 2014;44:947-54.

9. Kiesel K, Plisky PJ, Voight ML. Can Serious Injury in Professional Football be Predicted by a Preseason Functional Movement Screen? N Am J Sports Phys Ther 2007;2:147-58.

10. Ardern CL, Webster KE, Taylor NF, Feller JA. Return to the preinjury level of competitive sport after anterior cruciate ligament reconstruction surgery: two-thirds of patients have not returned by 12 months after surgery. Am J Sports Med 2011;39:538-43.

11. Hegedus EJ, Cook CE. Return to play and physical performance tests: evidence-based, rough guess or charade? Br J Sports Med 2015;49:1288-9.
12. Bahr R. Why screening tests to predict injury do not workand probably never will...: a critical review.Br J Sports Med 2016;50:776-80.

13. Molano FJ. ¿Cuándo puedo volver a entrenar con el grupo?. In: Gómez P. El fútbol ¡no! es así.172:180. Futboldelibro 2014. Barcelona.

14. Reiman MP, Manske RC. Functional testing in human performance. Champaign, IL: Human Kinetics; 2009.

15. Noyes FR, Barber SD, Mangine RE. Abnormal lower limb symmetry determined by function hop tests after anterior cruciate ligament rupture. Am J Sports Med 1991;19:513-8.

16. Delorme TL, Watkins AL. Technics of progressive resistance exercise. Arch Phys Med Rehabil 1948;29:263-73.

17. Beekhuizen KS, Davis MD, Kolber MJ, Cheng MS. Test-retest reliability and minimal detectable change of the hexagon agility test. J Strength Cond Res 2009;23: 2167-71.

18. Bosco C, Luhtanen P, Komi PV. A simple method for measurement of mechanical power in jumping. Eur J Appl Physiol Occup Physiol 1983;50:273-82.

19. Cooper KH. Aerobics. New York: Bantam Books; 1969.

20. Balke B. A simple field test for the assessment of physical fitness. rep 63-6. Rep Civ Aeromed Res Inst US 1963 Apr:1-8.

21. Léger LA, Lambert J. A maximal multistage 20-m shuttle run test to predict VO2 max. Eur J Appl Physiol Occup Physiol 1982;49:1-12.

22. Probst H. Test par intervalles pour footballeurs. Revue Macolin 1989;5:7-9.

23. Bangsbo J. Entrenamiento de la condición física en el fútbol. Paidotribo: Barcelona; 1998.

24. Kline GM, Porcari JP, Hintermeister R, Freedson PS, Ward A, McCarron RF, et al. Estimation of VO2max from a onemile track walk, gender, age, and body weight. Med Sci Sports Exerc 1987;19:253-9.

25. Barber SD, Noyes FR, Mangine R, DeMaio M. Rehabilitation after ACL reconstruction: function testing. Orthopedics 1992;15:969-74.

26. Danelon F, Boldrini L, Canzi M, Pisoni D, Porcelli S, Roi $\mathrm{G}$, et al. Objective reference values for assessing functional recovery after injuries in amateur soccer players. American College Sports Medicine. Annual Meeting, Nashville, Tennessee, 2005.

27. Roozen M. Action-Reaction Illinois Agility Test. NSCA's Perform Training J 2003;3:5-6.

28. Barrow H, McGee R. A practical approach to measurement in physical education. Philadelphia: Lea \& Febiger; 1971. p. 175-8.

29. Pauole K, Madole K, Garhammer J, Lacourse M, Rozenek R. Reliability and validity of the t-test as a measure of agility leg power, and leg speed in college-aged men and women. J Strength Cond Res 2000;14:443-50.

30. Freeman MA, Dean MR, Hanham IW. The etiology and prevention of functional instability of the foot. J Bone Joint Surg [Br] 1965;47:678-85.

31. Gray GW. Lower extremity functional profile. Adrian, MI: Wynn Marketing; 1995. 
32. Hertel J, Braham RA, Hale SA, Olmsted-Kramer LC. Simplifying the star excursion balance test: analyses of subjects with and without chronic ankle instability. J Orthop Sports Phys Ther 2006;36:131-7.

33. Whitney SL, Marchetti GF, Morris LO, Sparto PJ. The reliability and validity of the Four Square Step Test for people with balance deficits secondary to a vestibular disorder. Arch Phys Med Rehabil 2007;88:99-104.

34. Lee Y. Competencies needed by Korean HRD master's graduates: a comparison between the ASTD WLP competency model and the Korean study. Human Resource Development Quarterly 2009;20:107-33.

35. Penfield RD, Peter R, Giacobbi J. Applying a Score Confidence Interval to Aiken's. Item Content-Relevance Index. Meas Phys Educ Exerc Sci 2004;8:213-25.

36. Ardern CL, Glasgow P, Schneiders A, Witvrouw E, Clarsen B, Cools A, et al. 2016 Consensus statement on return to sport from the First World Congress in Sports Physical Therapy, Bern. Br J Sports Med 2016;50:853-64.

37. Drust B, Impellizzeri F, Meyer T. Return to play decisions - a highly important albeit unsolved issue. J Sports Sci 2014;32:1205.

38. Matheson GO, Shultz R, Bido J, Mitten MJ, Meeuwisse WH, Shrier I. Return-to-play decisions: are they the team physician's responsibility? Clin J Sport Med 2011;21:2530.

39. Zambaldi M, Beasley I, Rushton A. Return to play criteria after hamstring muscle injury in professional football: a Delphi consensus study. Br J Sports Med 2017;51:1221-6.

40. Moir GL, Garcia A, Dwyer GB. Intersession reliability of kinematic and kinetic variables during vertical jumps in men and women. Int J Sports Physiol Perform 2009;4:317-30.

41. Myer GD, Paterno MV, Ford KR, Quatman CE, Hewett TE. Rehabilitation after anterior cruciate ligament reconstruction: criteria-based progression through the return-to-sport phase. J Orthop Sports Phys Ther 2006;36:385-402.
42. Chomiak J, Junge A, Peterson L, Dvorak J. Severe injuries in football players. Influencing factors. Am J Sports Med 2000;28:58-68.

43. Oberacker LM, Davis SE, Haff GG, Witmer CA, Moir GL. The Yo-Yo IR2 test: physiological response, reliability, and application to elite soccer. J Strength Cond Res 2012;26:2734-40.

44. Condello G, Minganti C, Lupo C, Benvenuti C, Pacini D, Tessitore A. Evaluation of change-of-direction movements in young rugby players. Int J Sports Physiol Perform 2013;8:52-6.

45. Hart NH, Spiteri T, Lockie RG, Nimphius S, Newton RU. Detecting deficits in change of direction performance using the preplanned multidirectional Australian football league agility test. J Strength Cond Res 2014;28:3552-6.

46. Chaouachi A, Manzi V, Chaalali A, Wong del P, Chamari K, Castagna C. Determinants analysis of change-ofdirection ability in elite soccer players. J Strength Cond Res 2012;26:2667-76.

47. Castagna C, Impellizzeri F, Cecchini E, Rampinini E, Alvarez JC. Effects of intermittent-endurance fitness on match performance in young male soccer players. Strength Cond Res 2009;23:1954-9.

48. Ortiz A, Olson SL, Roddey TS, Morales J. Reliability of selected physical performance tests in young adult women. J Strength Cond Res 2005;19:39-44.

49. Emery CA, Cassidy JD, Klassen TP, Rosychuk RJ, Rowe BH. Effectiveness of a home-based balance-training program in reducing sports-related injuries among healthy adolescents: a cluster randomized controlled trial. CMAJ 2005;172:749-54.

50. Plisky PJ, Rauh MJ, Kaminski TW, Underwood FB. Star Excursion Balance Test as a predictor of lower extremity injury in high school basketball players. J Orthop Sports Phys Ther 2006;36:911-9.

51. Hegedus EJ, McDonough SM, Bleakley C, Baxter D, Cook CE. Clinician-friendly lower extremity physical performance tests in athletes: a systematic review of measurement properties and correlation with injury. Part 2--the tests for the hip, thigh, foot and ankle including the star excursion balance test. Br J Sports Med 2015;49:649-56. 